\title{
Influence of Coating Thickness on the Formability of Annealed Aluminum 2024
}

\author{
Irfan Mahmood Khan ${ }^{1, *}$, Kinza Tahreem², Junaid Iqbal ${ }^{2}$, Zeeshan Mehmood Khan ${ }^{2}$, Fatima Anjum ${ }^{1}$, \\ Abdul Mateen ${ }^{2}$ \\ ${ }^{1}$ IEM, Université de Montpellier, Montpellier, France \\ ${ }^{2}$ Institute of Space Technology, Islamabad, Pakistan
}

*Corresponding author: E-mail: irfan.khan@etu.umontpellier.fr

DOI: 10.5185/amlett.2020.081544

Sheet metal forming of uncoated Aluminum 2024 (Al-2024-TO) alloy was performed on conventional press with a movable punch. A set of four uncoated aluminum specimens (UCS) was formed after the application of silicone-based lubricant on the specimen surface facing punch. Variation in thickness of the specimens at different locations was one of the major concerns during forming operation which caused localized thinning and hardening of stock, resulting in a premature fracture $(100 \mathrm{~mm}$ depth). Thin porous membranes were deposited on the specimens to enhance lubrication (by retaining the lubricant) and reduce friction between clamp and stock. Four sets of coated specimens (CS) with different film thicknesses $(5 \mu \mathrm{m}, 10 \mu \mathrm{m}, 15 \mu \mathrm{m}$, and $20 \mu \mathrm{m}$ ) were anodized and formed to study the effect of coating thickness and lubricant entrapment on the formed depth. Characterization of coated specimens operation exhibited that the porous thin film with an optimum thickness of $10 \mu \mathrm{m}$ (pore diameter of 60-68 nm) facilitated the maximum entrapment of lubricant in the pores. Enhanced lubrication for CS-2 resulted in the aggravated material flow which showed minimum hardness $(60 \mathrm{HV})$, minimum thickness variation $(2.82-2.90 \mathrm{~mm})$, and minimum draw force $(11 \mathrm{kN})$ with the maximum draw depth of $172 \mathrm{~mm}$.

\section{Introduction}

There is a broad range of components, both in size and intricacy that can be fabricated from sheet metals, usually produced in huge amounts by conventional forming processes on mechanical presses. There are several types of sheet metal forming methods i.e., cutting, bending, and drawing. In sheet metal forming methods, the primary forces are normally tensile, with secondary compressive forces established by the reaction of a workpiece. Schuler [1] stated that metal flow in drawing operations (e.g., wire drawing, tube drawing, and deep drawing) is usually under the combined stress state, i.e. both tension and compression. Moreover, they are also of the opinion that the formability of the material can be varied by varying process parameters, e.g., draw force, draw pressure, friction, etc. This paper also focuses on varying process parameters to improve the formability of Al-2024-TO.

Gulati et al. [2] established that conventional sheet metal forming processes involve high costs and lead times due to the design and development of component-specific tooling. Incremental sheet metal forming reduces these factors, especially for small batch size production. However, conventional sheet metal forming can be the most suitable choice for batch production (either small or big) of components with same dimensional requirements. Mrad et al. [3] have discussed that thinning of the sheet is a major concern during sheet metal forming which can be reduced by optimizing stock-holder clearance, friction between stock-holder and stock, and the distance between punch and die. This study focuses on optimizing the punch-die and stock-stock-holder frictions. Zhang et al. [4] found that higher strain rate results in hardening of the alloy which reduces the formability of the alloy while lower strain rates tend to enhance the forming limit of the alloy. Naka et al. [5] found that the effect of the strain rate is more significant at elevated temperatures, however, this effect is insignificant at room temperature. Khan et al. [6] stated that cold working operation (e.g., sheet metal forming) can result in strain hardening of the work-hardened aluminum alloys (e.g., Al-2024, Al-6061, etc.).

The formability of an alloy is its ability to be drawn into desired shapes by the application of a certain load. Formability is dependent on various factors including draw force, lubrication, material flow, alloy composition, alloy temper (e.g., T3, T6, TO, etc.) and surface morphology of the sheet. Sheet metal forming is a common process in manufacturing and is the desired method for the fabrication of cylindrical heads and hemispherical cups. Extensive research work is accessible on the forming of aluminum alloys. The formerly available research barely covers the thorough optimization of process parameters in conventional forming processes to achieve the forming of deep drawn hemispherical cups. Mohamed et al. [7] stated that non-uniform punch stroke coupled with insufficient draw force (pressure) resulted in wrinkling of the formed specimen. In the current study, we ensured the application of sufficient draw force and uniform punch-stroke. Forming operation parameters may be tuned to yield optimal 


\section{Advanced Materials Letters www.vbripress.com/aml}

thickness along radius and depth of formed part including tolerable wrinkling. Modifications in lubrication can change the mode and pattern of material flow during forming, eliminate or create defects, modify product properties, alter the surface finish, and dimensional accuracy of the product.

Heat treatable aluminum alloys including AA7xxx, AA6xxx, and AA2xxx are suitable for manufacturing aerospace and automotive components due to their higher strength to weight ratios compared to other alloys [8]. Precipitation hardenable alloys are typically formed in T4 (naturally aged) and TO (annealed) conditions and seldom formed in the peak aged (T6 or T8) conditions due to higher strength and low ductility of T6 and T8 tempers [9].

Tang et al. [10] fabricated a porous membrane that served as a lubricant retention layer on the metal stock being formed. A two-phase $\mathrm{Zn}$-Sn alloy was coated on the stock followed by the selective etching of one of the components leaving behind a micro-layer. This microporous layer helped in the retention of lubricants in the form of small reservoirs which strongly facilitated the material flow during forming operation. Gautam et al. [11] performed forming operations in different conditions which included uncoated and coated stocks. Giffard et al. [12] studied and compared the properties of Al-1050 and Al2024 alloys anodized with porous alumina films.

In the current study, the impact of coating thickness during the forming of Al-2024-TO will be demonstrated and parameters will be examined and optimized. Process parameters such as coating thickness, draw force, draw depth, and thinning of stock are optimized to achieve a perfect combination of process parameters. Draw-depth of the stock concerning different coating thicknesses will be investigated in this study.

\section{Materials and methods}

\section{Equipment and raw materials}

The conventional forming press was employed for the forming of Al-2024. The unaltered downward velocity of punch was approximately $3 \mathrm{~mm} / \mathrm{s}$ while draw force ranged between 11-13 kN. The die-punch assembly is manufactured from K-100 cold worked tool steel. The press operates on hydraulic principles and hydraulic brakes are responsible for holding the punch in its position. Threaded screws are used to bind clamp plates with a die to render it immobile. Characteristics and features of the press are illustrated in Table 1 and Fig. 1.

The stockholder restricts the lateral and upward slippage of the stock to obtain uniformly formed specimens. Characteristics of the press are illustrated in Table 1.

Table 1. Press parameters and their values during the forming operation.

\begin{tabular}{ccc}
\hline Sr. No. & Press Parameters & Value $(\mathbf{m m})$ \\
\hline 1 & Punch diameter & 376.6 \\
2 & Die diameter & 383.3 \\
3 & Clearance & 3.35 \\
4 & Die Radius & 15 \\
5 & Stroke Size & $5-30$ \\
\hline
\end{tabular}

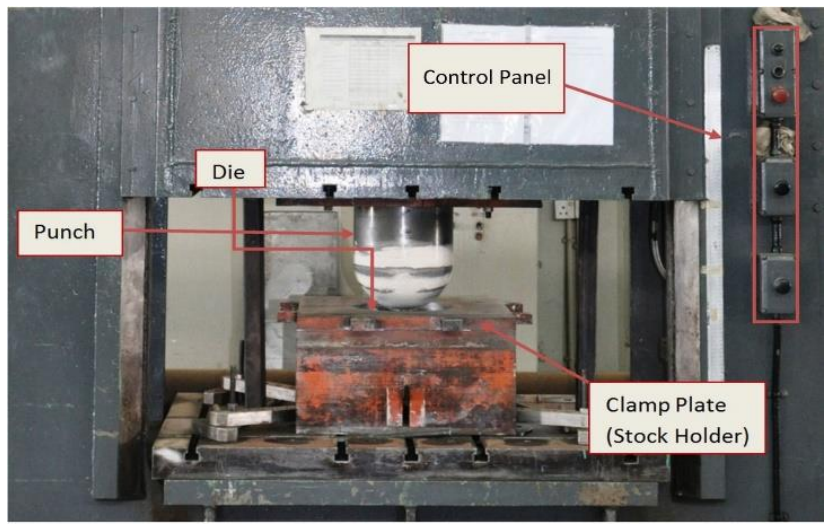

Fig. 1. Hydraulic press and its components.

Aluminum 2024 in annealed form was used as a forming stock (Length $\mathrm{x}$ Width $400 \mathrm{x} 400 \mathrm{~mm}$; thickness: $3 \mathrm{~mm}$ ) while $\mathrm{K}-100$ steel was used as a punch tool. Molykote ${ }^{\circledR}$ (silicone-based lubricant) was used as a lubricant during the whole forming operation. Copper and magnesium are major alloying elements in aluminum alloy while chromium is the significant alloying element in K-100 steel.

\section{Experimental procedure}

Five sets of samples of Al-2024-TO (dimensions: 600 x 600 x $3 \mathrm{~mm}$ ) were cut from the aluminum 2024-TO sheet. Each set consisted of four samples prepared in the same pattern to obtain reproducible results.

For the anodizing procedure, it is standard practice to prepare the substrate surface to improve coating adhesion. The main purpose of the surface preparation is to roughen the surface to improve coating-substrate interaction and to reduce/remove the inherent oxide layer present along an aluminum alloy surface. Coated AA2024-TO test specimens were prepared in several different forms to allow for preliminary coating microstructure and adhesion testing, in addition to forming of the specimens. Specimens designated for coating microstructure analysis were machined to $25 \times 25 \times 3 \mathrm{~mm}$ dimension.

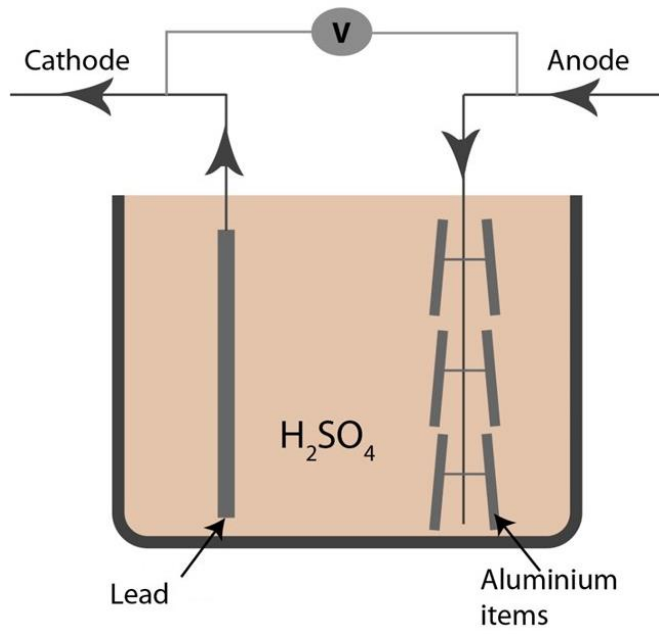

Fig. 2. Schematic illustration of the anodizing process. 


\section{Advanced}

\section{(A) $\mathrm{AAM}^{\oplus}$ \\ www.iaamonline.com}

The coating process (Fig. 2) mainly consisted of three successive steps including degreasing, etching, and anodization. All the aluminum alloy sheets (CS-1, CS-2, CS-3, and CS-4) were degreased initially by acetone followed by 20 minutes retention in an aqueous bath (at $60 \pm 2^{\circ} \mathrm{C}$ and $\mathrm{pH} \approx 9$ ) containing sodium tripolyphosphate (i.e., $\mathrm{Na}_{5} \mathrm{P}_{3} \mathrm{O}_{10}$ at $40 \mathrm{~g} / \mathrm{L}$ ) and sodium tetraborate (i.e., $\mathrm{Na}_{2} \mathrm{~B}_{4} \mathrm{O}_{7}, 10 \mathrm{H}_{2} \mathrm{O}$ at $40 \mathrm{~g} / \mathrm{L}$ ). Finally, the specimens were etched for 5 minutes in an aqueous solution of sulphoferric (at $25 \pm 5^{\circ} \mathrm{C}$ and $\mathrm{pH} \approx 2$ ). The samples were frequently rinsed with distilled water at ambient temperature after every step. The aluminum specimen was immersed in an electrochemical cell as an anode while the lead plate was used as a cathode in the cell, consisting of aqueous sulfuric acid stirred bath (at $200 \mathrm{rpm}$ and having molarity of $2.039 \mathrm{~mol} / \mathrm{L}$ ). The electrochemical solution was thermostated with a $\mathrm{CC} 2$ Huber cryostat at $20.0 \pm 0.5^{\circ} \mathrm{C}$. The anodization operation was carried out in potentiodynamic mode at a preliminary voltage ramp (i.e., 0-16 V, $0.05 \mathrm{~V} / \mathrm{s}$ and $320 \mathrm{~s}$ ) [12].

Four samples with different thicknesses were prepared using the anodizing process by maneuvering the process parameters (i.e., time and voltage). The average thicknesses of Coated Sample-1 (CS-1), CS-2, CS-3, and CS-4 were $5 \mu \mathrm{m}$ (at $4 \mathrm{~V}$ and 20 minutes), $10 \mu \mathrm{m}$ (at $8 \mathrm{~V}$ and 30 minutes), $15 \mu \mathrm{m}$ (at $12 \mathrm{~V}$ and 40 minutes), and $20 \mu \mathrm{m}$ (at $12 \mathrm{~V}$ and 50 minutes), respectively. The average coating thickness was measured with a non-destructive technique using Elcometer 456 at 4 different locations of each sample.

Fig.3 (a) shows the schematic illustration of forming operation while Fig. 3(b) shows the formed specimens. The forming operation was initially performed on the Uncoated Sample (UCS). The stock (Dimensions: $600 \times 600 \times 3 \mathrm{~mm}$ ) was mounted in stockholder above the die. To counter the lateral and upward movement of the stock the Clamp plate was fitted above the stock. 12 layers of rubber pads were placed around the die for hindering the punch speed; after every $30 \mathrm{~mm}$ depth, each layer was detached. The pads were stacked around the periphery for damping high impact loads and lowering the punch speed. Punch was moved down gently which pressed the stock up to the depth of step size ranging from $5 \mathrm{~mm}$ to $30 \mathrm{~mm}$. Spacers (dimension: $100 \times 25 \times 3.2 \mathrm{~mm}$ ) were placed around the stock to absorb the extra clamp-force exerted by the portion of the downward moving press adjacent to the punch. A siliconebased lubricant (Molykote®) was applied on the top side of the sample which was in contact with the clamp holder. No lubricant was used in the middle of the stock to give optimal friction between stock and punch for the material flow. It was observed that lubricant enhanced the material flow and decreased friction on the edges of the stock. A formed sample (UCS) with a depth of $100 \mathrm{~mm}$ was obtained before its fracture.

The same procedure was followed for forming coated samples (CS-1, CS-2, CS-3, and CS-4) and formed (draw) depth was measured. The draw depths of $150 \mathrm{~mm}, 172 \mathrm{~mm}$, 160 , and $152 \mathrm{~mm}$ were attained for coated samples CS-1, CS-2, CS-3, and CS-4, respectively.

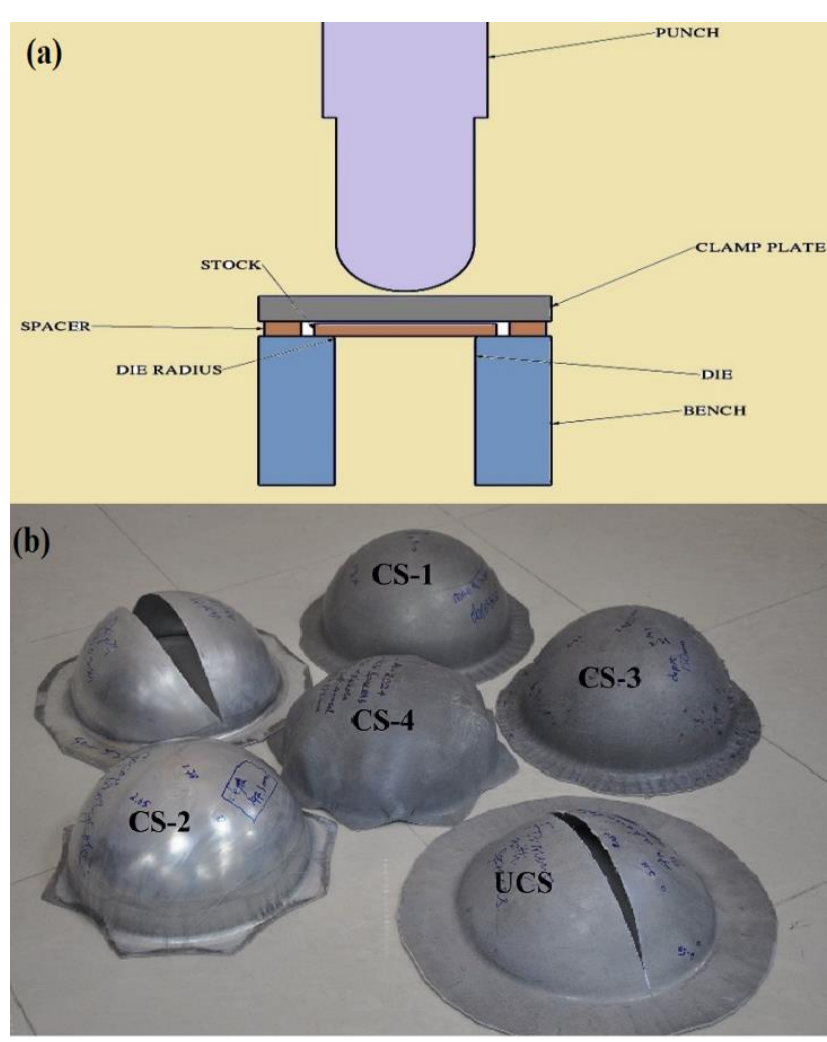

Fig. 3. (a) Schematic illustration of forming operation (b) Image of the formed specimens.

\section{Results and discussion}

Characterization of all the Al-2024-TO specimens was carried out to investigate their properties. Five different characterization techniques were implemented to analyze the formability of the Al-2024-TO alloy. The effect of different parameters on formability and draw-depth of the specimens was studied to achieve the most suitable combination of parameters. Following characterization techniques were used to investigate Al-2024-TO specimens:

1. Scanning Electron Microscopy (SEM) Analysis

2. Pull-Of adhesion Test

3. Hardness Measurement

4. Draw Force and Draw Depth Measurements

5. Thickness Measurements

Initially, the characterization of the deposited film was carried out for all the coated specimens including CS-1, CS2, CS-3, and CS-4. The first two techniques mentioned above were used for coated specimens only. The microstructure, pore diameter, and coating thicknesses were investigated using the JSM-500HR InTouchScope ${ }^{\mathrm{TM}}$ Scanning electron microscope (SEM). SEM micrographs of four coated specimens are shown below:

The cross-sectional view of the samples was examined by SEM to measure the thickness of multilayers along-with structural and porosity analysis. Fig. 4(a) shows the porous coatings structures of all the specimens. The values of coating thicknesses in all samples were different as explained earlier in the experimental procedure. This was 


\section{Advanced Materials Letters www.vbripress.com/aml}

because of the variation in coating duration and voltage. The thicknesses of all coated samples were in the range of $5 \mu \mathrm{m}$ to $20 \mu \mathrm{m}$. The thickness values for CS-1, CS-2, CS-3, and CS-4 were $5 \mu \mathrm{m}$. $10 \mu \mathrm{m}, 15 \mu \mathrm{m}$, and $20 \mu \mathrm{m}$, respectively (Fig. 4a). These thickness values comply with the values measured with Elcometer 456 after the coating deposition. The thickness of layers plays an important role in the lubrication efficiency of the layers. Four sets of specimens with four different pore diameters were prepared for microstructural investigation (due to different etching times). All the specimens in each set contained almost the same overall porosity due to homogeneous pore size variation in a short-range (e.g., all of the four CS-4 specimens with pore sizes between $80-88 \mathrm{~nm}$ contained almost same overall porosity). Pore $\%$ in Fig. 4(c) represents the percentage of pores with a specific diameter (i.e., $80-81 \mathrm{~nm}, 30-31$, etc.) and the sum of all pore percentages (for a particular specimen) with different pore diameters equal to 100. It can be observed from Fig. 4(b-c) that the specimens show distinct pore diameter ranges. CS2 shows a more homogenous distribution of pore diameters (ranging from $60 \mathrm{~nm}$ to $68 \mathrm{~nm}$ ). On the other hand, $80 \%$ of the pores in CS-3 have the same diameter $(49-50 \mathrm{~nm})$ while the remaining $20 \%$ exhibit different pore diameters (47-48 $\mathrm{nm}$ and 51-52 nm). Pore diameter distribution for CS-1 and CS-4 is comparable to each other; however, both of these pore diameters show lower and upper extremes (i.e., 30-38 $\mathrm{nm}$ for CS-1 and 80-88 $\mathrm{nm}$ for CS-4).

(a)

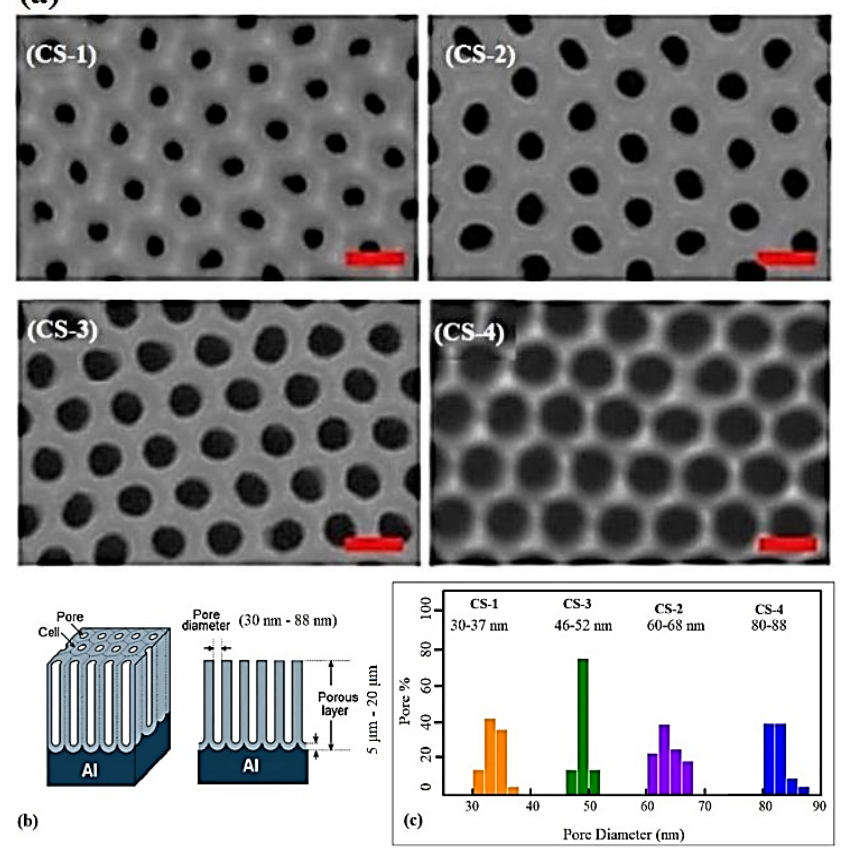

Fig. 4. SEM micrographs of coated specimens (a) porous film textures (b) pore diameter and coating depth (c) pore distribution.

Pull-Off Adhesion Test was performed to evaluate the adhesion strength of coatings (Fig. 5). The key components of a typical pull-off adhesion test equipment are a pressure source, an actuator, and a pressure gage. During the testing operation, the surface of the dolly is glued to the coating surface. After the curing of the bonding glue, a coupling connector is connected with the dolly, and pressure source is activated. The dolly is pulled-off from the surface when the pressure exceeds the coating-substrate bonding strength.

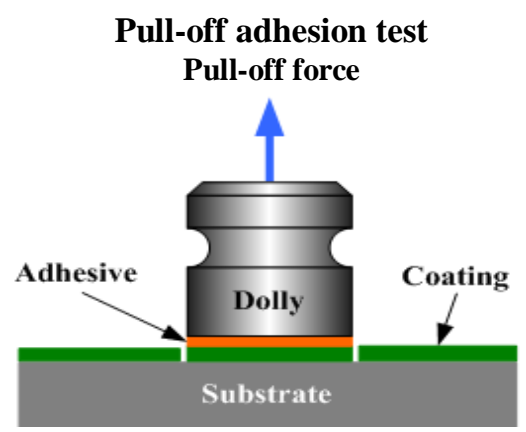

Fig. 5. Mechanism of Pull-off adhesion test.

Eler 106 Pull-Off Adhesion Tester was used to carry out the tests. Adhesion testing was carried out as per ASTM D 4541 and BS EN ISO 4624 standards. The tensile pulloff technique for adhesion testing involved bonding a test dolly to the coated specimen using a glue (Loctite Hysol E214HP). After the gluing process, the dolly was removed along with the coating by applying a perpendicular (pulling) force. The pulling force and detached coating area determine the characteristics of the coating. The measured pull-off adhesion force directly determined the adhesion strength between the substrate and the coating. The adhesion strength and percentage detached area of the coating surface is illustrated in Table 2 and Fig. 6, respectively.

Table 2. Adhesion test results for coated specimens.

\begin{tabular}{cccc}
\hline Specimen & $\begin{array}{c}\text { Coating } \\
\text { Thickness }(\boldsymbol{\mu m})\end{array}$ & $\begin{array}{c}\text { Average Adhesion } \\
\text { Strength }(\mathbf{M P a})\end{array}$ & $\begin{array}{c}\text { Detached } \\
\text { Area }(\%)\end{array}$ \\
\hline CS-1 & 5 & 150 & 20 \\
CS-2 & 10 & 143 & 26 \\
CS-3 & 15 & 118 & 65 \\
CS-4 & 20 & 110 & 80 \\
\hline
\end{tabular}

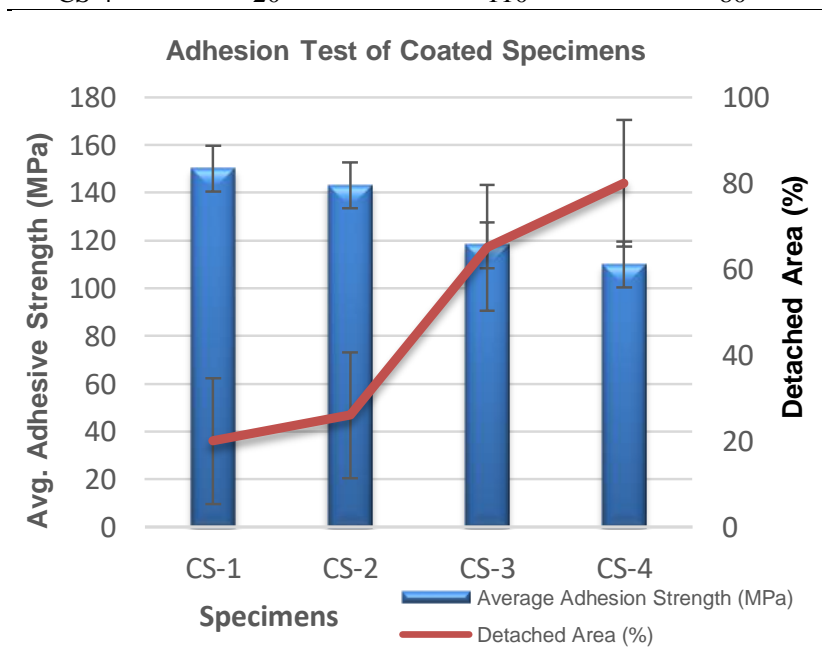

Fig. 6. The adhesion strength and percentage detached area of coated specimens. 


\section{Advanced Materials Letters www.vbripress.com/aml}

It can be observed from the above data that adhesion strength is higher at lower thickness values and vice versa. On the other hand, the detached surface area increases as the adhesion-strength decreases. CS-1 and CS-2 show comparably higher adhesion strength $(150 \mathrm{MPa}$ and 143 $\mathrm{MPa})$ and a lower percentage detached area (20\% and $26 \%)$. On the other hand, CS-3 and CS-4 show lower values of adhesion strength (118 MPa and $110 \mathrm{MPa})$ and percentage detached surface area $(65 \%$ and $80 \%)$. It can be deduced that an increase in coating thickness results in a decrease in adhesion strength and vice-versa. Lower adhesion strength in thicker coatings is usually associated with the increased residual stresses present in thicker coatings [13].

Chromik et al. [14] illustrated that adhesion strength depends on surface roughness and porosity. All of the specimens were grit blasted before the application of a coating to uniformly roughen the surfaces. Therefore, higher adhesion strength of CS- 1 and CS- 2 can be attributed to smaller pore diameters and lower thicknesses.

The rise in hardness values of Al-2024 is associated with a cold working (forming) operation which ultimately increases the strain hardening for the given temper. Strain hardening of the alloy increases its hardness and strength values by compromising its ductility. Different zones at the formed specimen exhibit different hardness values. Maximum strained areas show maximum hardness and vice versa. UCS shows maximum hardness values at the center of the formed hemisphere and minimum at edges.

Ultrasonic Hardness Tester SU-300 was used for hardness testing of the formed specimens. This hardness tester conforms to the ASTM A1038-2005 standard. The hardness of the formed specimens was measured along the curvature, i.e. from the center of the hemisphere to its edges at four different locations. Specimens showed a decrement in hardness values as traversed from the center of the curvature to the edges of the hemisphere.

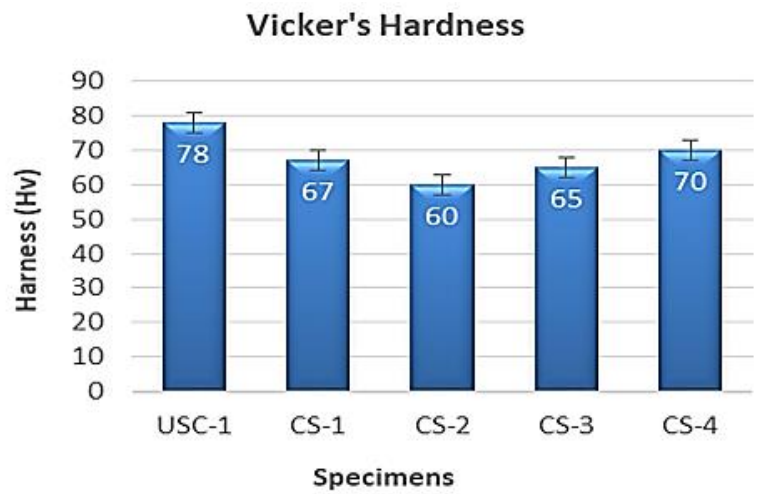

Fig. 7. Average hardness values for all formed specimens of Al-2024-TO.

According to Siqueira et al. [15], the strength and hardness of the Al-2024 alloy increase as a result of cold working and age hardening [15]. The hardness of the specimen increased during cold working as indicated in the graph above (Fig. 7). It is evident that UCS shows the highest hardness $(78 \mathrm{HV})$ due to the highest restriction in material flow at the edges of the specimen owing to the excessive clamping force; ultimately, resulting in thinning of the hemisphere at the center. This is due to the lower entrapment of the lubricant between the clamp plate and the stock. On the other hand, the incorporation of porous films resulted in higher retention of the lubricant between the stock and the clamp plate. Therefore, all the coated specimens (CS-1, CS-2, CS-3, and CS-4) exhibited higher formability and lower hardness as compared to the uncoated specimen. The lowest clamping resistance (hence lowest hardness and higher formability) was observed for CS-2 $(60 \mathrm{HV})$ due to the highest retention of the lubricant on the surface of the specimen which significantly reduced the friction between the stock and the clamp plate. The hardness values of CS-1, CS-3, and CS-4 (67 HV, $65 \mathrm{HV}$ and, $70 \mathrm{HV}$ ) are comparable with each other.

Maximum hardness values for all the specimens were observed at the potential fracture location, which underwent maximum thinning. Cumulative standard deviation calculation in the hardness of all TO samples is given by the following formula:

Average hardness values for all samples $(\mathrm{HV})=\mathrm{H}=[7867$ $606570]$

Mean Hardness $=\mu=68$

No. of Samples $=\mathrm{N}=5$

Standard Deviation $=\mathrm{S}=\sqrt{\frac{\sum_{i}^{5}(H-\mu)^{2}}{N-1}}=>\mathrm{S}=5.97$

It is worthwhile to mention here that the thickness and pore distribution of the porous film played an important role in retaining the substantial amount of lubricant required for reducing the clamp-force and increasing the material flow. Draw force was recorded during the forming operation of each specimen and draw-depths were measured using measurement gauges after the forming operation. Fig. 8 shows the relationship between draw force and draw depth for all the formed specimens.

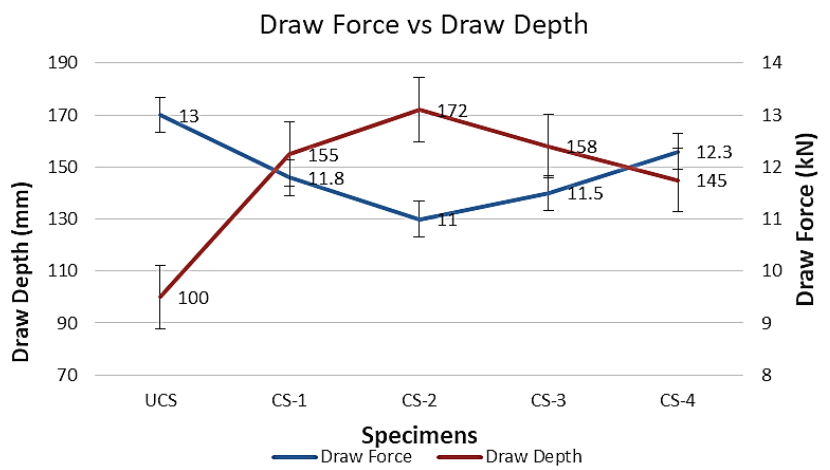

Fig. 8. Graph showing Draw-depths with respect to draw forces for the formed specimens.

Draw force for UCS is highest while draw depth for this specimen is the lowest which is due to the reason stated above, i.e., highest clamping force and lowest material flow due to absence of sufficient lubricant. On the other hand, draw force for the coated specimens significantly reduced with a noticeable increase in the draw depths. CS-1 and CS4 have the lowest and the highest film thicknesses with comparable draw depths $(150 \mathrm{~mm}$ and $145 \mathrm{~mm})$ and draw 


\section{Advanced Materials Letters www.vbripress.com/aml}

forces (12 kN and $12.3 \mathrm{KN})$. CS-3 shows relatively super characteristic (Draw force: 11.5; Draw depth: $160 \mathrm{~mm}$ ) as compared to CS-1 and CS-2 due to uniform pore diameters ( $80 \%$ pores have the same diameter of $49-50 \mathrm{~nm}$ ). On the other hand, CS-2 excellent characteristics among all the specimens. This is due to comparatively lower draw force, lower hardness, higher lubricant retention (due to homogenous pore distribution and optimum coating thickness), and higher draw depth (Fig. 8). In the case of thicker films, it can be deduced that CS-3 and CS-4 could not release the required amount of lubricant onto the surface due to deeper pores. It can also be deduced that a porous film above a certain thickness and pore diameter becomes less useful which does not improve the formability of the alloy by providing sufficient lubrication.

The variation in thickness of the specimen indicates the extent of cold work and thinning induced due to forming operation. The variation in thickness is a direct manifestation of material flow. Similar to the results obtained by Gautam et al. [11], uniform material flow results in less thickness variation while non-uniform material flow yields in the thinning of sheets. The highest reduction in the thickness $(1.9-2.15 \mathrm{~mm})$ of the specimen is observed for UCS due to the highest degree of cold work. On the contrary, the lower thickness variation is observed for coated specimens, especially, CS-2 (2.82-2.90).

The disparity in a formed depth is not directly associated with the ductility of the alloy. It refers to inconsistency in material flow, i.e. the specimen formed up to the depth of $172 \mathrm{~mm}$ showed a thickness reduction of $0.10-0.18 \mathrm{~mm}$ (low-level strain) while that formed to the depth of $100 \mathrm{~mm}$ showed a thickness reduction of 0.85-1.10 $\mathrm{mm}$ (high-level strain). Constrained material flow at high repetitive loads resulted in strain hardening of the alloy. Thickness variation in the formed specimens is demonstrated in Table 3 and Fig. 9 below:

Table 3. Thickness variation for drawn/formed specimens.

\begin{tabular}{ccccc}
\hline Specimen & $\begin{array}{c}\text { Initial Thickness } \\
(\mathbf{m m})\end{array}$ & $\begin{array}{c}\text { Coating } \\
(\boldsymbol{\mu m})\end{array}$ & $\begin{array}{c}\text { Final Thickness (mm) } \\
\text { Lower Limit }\end{array}$ & Upper Limit \\
\hline UCS & 3 & - & 1.90 & 2.15 \\
CS-1 & 3 & 5 & 2.65 & 2.72 \\
CS-2 & 3 & 10 & 2.82 & 2.90 \\
CS-3 & 3 & 15 & 2.75 & 2.80 \\
CS-4 & 3 & 20 & 2.20 & 2.40 \\
\hline
\end{tabular}

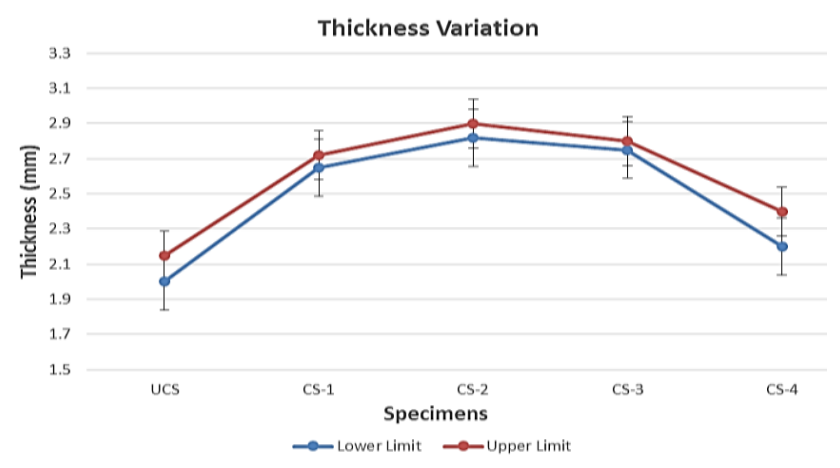

Fig. 9. Graph showing thickness variation in drawn/formed specimens with an initial thickness of $3 \mathrm{~mm}$.
It can be observed from the above data that CS- 1 and CS-3 show a moderate reduction in the thickness while UCS and CS-4 show extreme thickness reductions. However, CS-2 shows the most promising results.

The characterization data presented above illustrates that there are several factors that influence the formability of Al-2024-TO alloy. The use of lubricant improves the formability of the alloy by increasing the material flow from the edges of the stock. However, insufficient lubricant retention results in lower material flow and ultimately the lower formability. UCS showed the lowest draw depth $(100 \mathrm{~mm})$, the highest thickness reduction $(0.85-1.10 \mathrm{~mm})$, and the highest hardness values $(78 \mathrm{HV})$ due to lower entrapment of lubricant between UCS stock and clamp plate. Among the coated specimens the highest hardness $(70 \mathrm{HV})$ and the lowest draw depth $(145 \mathrm{~mm})$ were observed for CS-4. CS-1 and CS-3 showed mediocre hardness (67 HV and $65 \mathrm{HV}$ ) and draw depth values $(155 \mathrm{~mm}$ and $158 \mathrm{~mm})$. Finally, CS-2 shows the highest draw depth $(172 \mathrm{~mm})$ and the lowest hardness $(60 \mathrm{HV})$ values. The above results show that the coated specimens entrapped more lubricant as compared to UCS. However, the maximum lubricant entrapment was observed for CS-2.

The entrapment of lubricant depends on percentage porosity, pore size distribution, and thickness of the coated film. Since the percent porosity of all the specimens was the same, the pore size distribution and thickness of the film played a significant role in lubricant entrapment. SEM analysis of the coated specimens illustrates that CS-2 shows excellent lubricant entrapment due to its optimum film thickness $(10 \mu \mathrm{m})$ and optimum pore size distribution (60-68 nm). Finally, the adhesion strength strongly relies on the thickness of the film. Higher the thickness, lower the strength (due to residual stress present in thicker films). The results of pull-off adhesion test exhibited that CS-1and CS2 showed considerably lower percentage detached area (20\% and 26\%) and higher adhesion strength (150 MPa and $143 \mathrm{MPa}$ ) than CS-3 and CS-4 (with a detached area of 65\% and $80 \%$ along with adhesion strength of $118 \mathrm{MPa}$ and 110 $\mathrm{MPa}$, respectively). It is evident from the experimental results and characterization data that CS-2 showed excellent characteristics in terms of sheet metal forming due to its customized properties. Similar to the results obtained by Tang et al. [10], the modifications in coating thickness resulted in approximately $70 \%$ improvement in the formability of the alloy (i.e., from $100 \mathrm{~mm}$ to $172 \mathrm{~mm}$ of the formed depth).

\section{Conclusion}

Experimental results exhibited the improvement in the material flow and formability of alloy by altering the coating thickness for enhanced entrapment and release of the lubricant on the surface of the stock. It was observed from the experiments that uncoated aluminum specimen (UCS) underwent maximum strain hardening and showed the most inferior forming characteristics, i.e., the lowest draw depth $(100 \mathrm{~mm})$, the highest hardness $(78 \mathrm{HV})$, the highest draw force $(13 \mathrm{kN})$ and the highest thickness 


\section{Advanced Materials Letters www.vbripress.com/aml}

reduction (0.85-1.10). On the other hand, the characterization of coated specimens exhibited that the deposition of a porous thin film on the aluminum specimen significantly improved the formability of the alloy.

It was observed via SEM analysis that a coated specimen (CS-2) having a coating thickness of $10 \mu \mathrm{m}$ and the pore diameter of $60-68 \mathrm{~nm}$ facilitated the maximum entrapment of the lubricant in the pores which resulted in enhanced material flow and the minimum strain hardening. The superior characteristics of CS-2 were due to the lowest hardness $(60 \mathrm{HV})$, the lowest thickness variation (0.10-0.18 $\mathrm{mm})$, and a minimum draw force $(11 \mathrm{kN})$ for achieving a maximum draw depth of $172 \mathrm{~mm}$ (up to $70 \%$ higher than UCS). The pull-off adhesion test results show that CS-2 exhibits reasonable adhesion strength (143 MPa) with an optimum thickness $(10 \mu \mathrm{m})$ which is comparable to the adhesion strength of CS-1 (150 MPa) which has a lower thickness $(5 \mu \mathrm{m})$.

\section{Data availability statement}

The raw/processed data required to reproduce these findings cannot be shared at this time as the data also forms part of an ongoing study.

\section{Conflict of interest Statement}

The authors declare that they have no conflict of interest.

\section{Keywords}

Annealed, draw depth, draw force, lubricant, material-flow, hardening, thin film.

Received: 22 March 2020

Revised: 27 April 2020

Accepted: 27 April 2020

\section{References}

1. GmbH Schule; Metal forming handbook. Springer Science \& Business Media, Heidelberg, Germany, 1998.

2. Gulati, V.; Aryal, A.; Katyal, P.; Goswami, A.; J. Inst Eng (India): Series; 2016, C 97, 185.

3. Mrad, H.; Ayed, L.B.; Bouazara, M.; Int. J. Adv. Res. Technol. (IJERT), 2015, 4, 565.

4. Zhang, C.; Leotoing, L.; Guines, D.; Ragneau, E.; J. Mater. Proc. Technol., 2009, 209, 3849.

5. Naka, T.; Torikai, G.; Hino, R.; Yoshida, F.; J. Mater. Proc. Technol., 2001, 113, 648 .

6. Khan, I.M.; Ismail, U.; Noman, D.; Siddiqui, M.Z.; Shahzad, M.; J. Sp. Technol., 2017, 7, 7.

7. Mohamed, M.; Carty, D.; Storr, J.; Zuelli; N.; Blackwell, P.; Key Eng. Mater; 2016, 716, 685.

8. Zheng, K.; Politis, D.J.; Wang, L.; Lin, J.; Int. J. LW. Mater. \& Manuf., 2018, 1, 55.

9. Fine, M.E.; Metall. Trans. A, 1975, 6, 625.

10. Tang, P.T.; Arentoft, M.; Bay, N.; Borrild, M.J.; Mizushima, I.; Dai Jensen, J.; Paldan, N.A.; U.S. Patent Application No. 12/452,118, 2010.

11. Gautam, B.; Chandra, V.; Kumar, P.; Agrawal, N.; Kumar, S.; Int. J. Curr. Eng. Technol., 2016, 6, 46.

12. Giffard, K.; Arurault, L.; Blanc, C.; Di Caprio, D.; Surf. Interface Anal.; 2019, 51, 1184.

13. Sharma, M.M.; Eden, T.J.; Golesich, B.T.; J. Therm. Spray Technol., 2015, 24, 410 .

14. Chromik, R. R.; Goldbaum, D.; Shockley, J. M.; Yue, S.; Irissou, E.; Legoux, J. G.; Randall, N.X.; J. Surf. Coat Technol., 2010, 205, 1409.

15. Siqueira, M. L.; Silva, A. D.; Melo, M. D. L. N. M.; Rodrigues, G.; Mater. Res., 2019, 22, 1. 